\title{
THE MORPHOLOGICAL RESPONSE OF BEACHES PROTECTED BY DIFFERENT BREAKWATER CONFIGURATIONS
}

\author{
Carlo Lorenzoni ${ }^{1}$, Matteo Postacchini ${ }^{2}$, Alessandro Mancinelli ${ }^{3}$ and Maurizio Brocchini ${ }^{4}$
}

\begin{abstract}
A series of experimental tests on a 2D movable-bed physical model of the protected sandy beach of Gabicce Mare, on the central Adriatic Sea in Italy, is described. Three emerged and three submerged configurations of rubble-mound detached breakwaters, for beach protection, placed at different positions, were tested in the Ancona (Italy) wave flume and the obtained results were compared with those found for a structure-free configuration. Both wave dissipation and reduction of beach erosion efficiency under various wave conditions were obtained and, in particular, the short-term hydro-morphodynamic response of the different tested breakwater configurations.
\end{abstract}

Keywords: coastal defence; rubble-mound breakwaters; maritime physical models

TRADITIONAL RUBBLE-MOUND STRUCTURES FOR COASTAL DEFENCE BREAKWATERS

The Adriatic coasts of Italy, are extensively protected, from beach erosion, by several defence structures. In fact, sandy beaches are their usual landscape, except for the littorals of Gargano, Conero and other smaller promontories. Hence, beach erosion is the main problem, which is reduced by coastal defences, that dissipate the approaching wave energy, especially by breaking. In particular, the $170 \mathrm{~km}$ of the Marches Region coast is protected by more than $100 \mathrm{~km}$ of defences (Istituto di Idraulica 2001).

Historically, the first coastal structures were emerged rubble-mound breakwaters, built, starting from the first half of the last century, to solve erosion phenomena. These problems were originated by other older nearshore coastal structures, especially shore-connected, which altered the natural sedimentary dynamic equilibrium of beaches, such as harbour jetties and then protections for railways either roads or recreational/tourist facilities (Lorenzoni and Mancinelli 2002). Emerged breakwaters induce undesired phenomena, such as tombolo and salient formation, mud and seaweed deposits, degradation of water quality, downdrift beach erosion, pronounced local seaward scour, aesthetical problems, etc. When geometrical features of these structures, i.e. distance from shoreline, berm extension, structure height, breakwater length, gap width, are correctly determined, the results are good in terms of shore protection, but one of the most important effects, the downdrift erosion, still remains.

Later, from about the first half of the ' $80 \mathrm{~s}$, in Italy and especially along the Marches coast, rubblemound submerged breakwaters were used for the new coastal defence plans (Lorenzoni et al. 1987). Such structures have a better visual/environmental impact on the landscape and reduce the wave energy impact on the beach, but this occurs at the expenses of swimmers' safety and of some aspects of shoreprotection efficiency. The nearshore circulation is strongly influenced by the presence of arrays of submerged barriers: in this case incident storm waves induce a intense circulation system with onshoredirected flows over the breakwaters and strong offshore-directed currents, called "rip currents", through the narrow gaps between the contiguous barriers of the array. Not only they reduce the efficiency of the beach protection, because they transport sediment seawards, but are also dangerous for swimmers' safety (Soldini et al. 2009). Other important limits are the downdrift erosion during storm events, sometimes comparable to that of emerged breakwaters, and the deep scours localized in the gap areas.

It is noticeable that, sometimes, along the Marches Region coasts, where arrays of submerged breakwaters were built during the ' $80 \mathrm{~s}$-' 90 s to protect long stretches of sandy or gravel beaches, this type of breakwaters have been recently replaced with emerged, more protective, structures. Therefore, downdrift erosion, local scours and rip currents are the most widely observed limits of traditional rubble-mound emerged and submerged breakwaters placed along the Italian coast of the Adriatic Sea.

Alternative solutions, that reduce both environmental impacts and construction/maintenance costs, are strongly required (Burcharth et al. 2007). In recent years many studies have been carried out on innovative structures that enable to reduce the sea storm effects on the beach, to guarantee, for instance,

${ }^{1}$ Università Politecnica delle Marche, Dipartimento I.C.E.A., via Brecce bianche, Ancona, Italy, 60131

${ }^{2}$ Università Politecnica delle Marche, Dipartimento I.C.E.A., via Brecce bianche, Ancona, Italy, 60131

${ }^{3}$ Università Politecnica delle Marche, Dipartimento I.C.E.A., via Brecce bianche, Ancona, Italy, 60131

${ }^{4}$ Università Politecnica delle Marche, Dipartimento I.C.E.A., via Brecce bianche, Ancona, Italy, 60131 
a positive nearshore circulation without loosing large amounts of sediments (Postacchini et al. 2011). Nowadays many new solutions and examples of defence structures can be observed all over the world: e.g. composite systems made of breakwaters and groins to form protected cells hosting nourishments, mound-shaped artificial reefs, made of pierced concrete balls, or geotubes, used as either detached structures or breakwater cores (Pilarczyk 2003). Other solutions have been studied and experimentally tested, e.g. submerged vertical or inclined blades (Lorenzoni et al. 2010).

Although the novel maritime solutions seem to give fairly good results for the nearshore circulation, traditional detached breakwaters, sometimes coupled with nourishments, are still largely employed to protect Italian beaches. Accurate studies on the behaviour of such structures is needed to improve their design applications, also taking into account the beach evolution during short-term events. This is appropriate for the specific conditions of Italian beaches, because strong events occur even in summer, leading to structural damages of tourist facilities that, too frequently, are built close to the shoreline.

Hydro-morphodynamic phenomena around traditional defence rubble-mound breakwaters are quite complex and articulated and have interactions with the swash zone dynamics. In particular, The erosion of the submerged beach is due to the wave-induced currents, while the morphodynamics of the emerged part of the beach depends mainly on the run-up or swash motions and, for beaches with coarser sediments, also on the permeability. The high energy generated run-up motion forces rapid morphological changes associated with the development of an emerged berm.

Both emerged and submerged barriers induce, during a sea storm, an increase of the mean water level in the inshore protected zone. This phenomenon is known as piling-up and the mechanism that generates it is quite complex and depends on various contributions that provide an equilibrium between inshore and offshore zones, as sketched in Fig. 1. For an emerged breakwater the piling-up is due to the water passing over $\left(Q_{o v}\right)$ and filtering through the structure $\left(Q_{i n}\right)$. This increase of the water level in the inshore area forces the water to filter out through the structure $\left(Q_{o u t}\right)$ and to flow through the narrow gaps between two contiguous barriers of an array, originating the rip current $\left(Q_{r}\right)$. With submerged barriers the mechanism is almost the same, though another outward component, allowing the water to flow over the freeboard $\left(Q_{f r}\right)$, is still important (Postacchini et al. 2010).

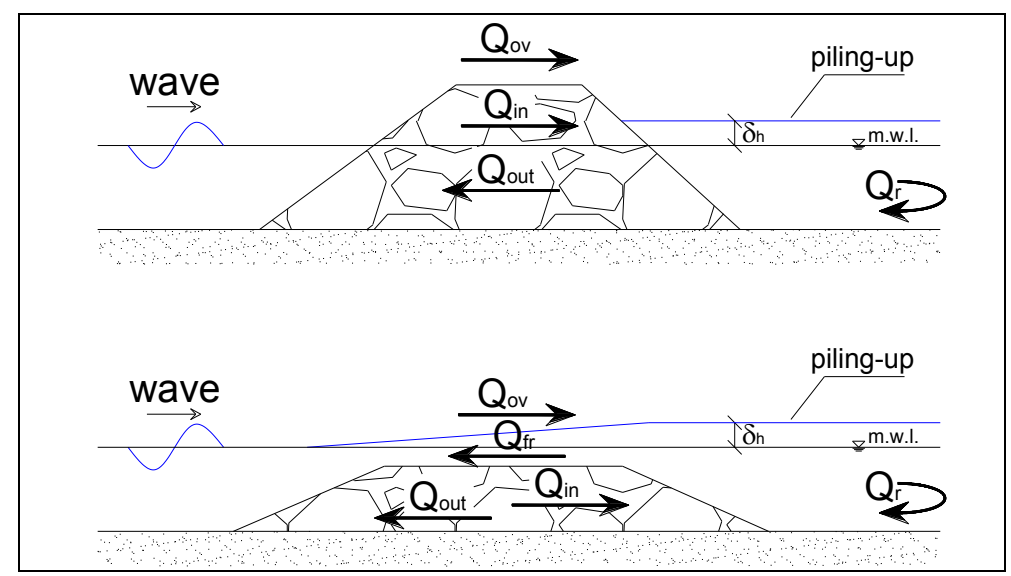

Figure 1. Sketch of the flows interesting the piling-up phenomenon in the presence of emerged (top panel) or submerged (bottom panel) breakwaters.

Several studies, collected in Burcharth et al. (2007), have been carried out to describe analytically the entire flux pattern for both submerged and emerged structures. Many tests have been carried out in 2D wave flumes, that enable estimates of the maximum piling-up, because of the laterally confined conditions, hence the tested breakwater can be seen as an infinitely long barrier in the reality. In 2D experimental tests the emerged breakwaters induce a piling-up in the protected zone and an outward flow through the structure that can be either associated with a recirculation flow $\left(Q_{r} \neq 0\right)$, representing the flow through the gaps, or single (confined configuration, $Q_{r}=0$ ). Ruol et al. (2003) carried out many tests and investigated several conditions, by running different wave types and by applying different recirculation conditions, starting from the confined condition $\left(Q_{r}=0\right)$ till the maximum recirculation, associated with a zero piling-up $(\delta h=0)$. The latter case refers to infinitely wide gaps, the confined 
condition to infinitely long breakwaters. A linear dependence was found between the piling-up $(\delta h)$ and the net transmitted discharge $\left(Q_{r}=Q_{o v}+Q_{i n}-Q_{o u t}\right)$, depending on the wave type.

According to the method of Calabrese et al. (2005), a balance equation governs the hydrodynamic equilibrium around a submerged breakwater:

$$
\Delta S_{x x}+\Delta \Pi+\Delta P=0
$$

where $\Delta S_{x x}$ is the radiation stress gradient for the $x$ component, $\Delta \Pi$ the mean force of the structure on the water volume and $\Delta P$ the hydrostatic thrust difference. Solution of (1) yields:

$$
\delta_{m}=0.5\left[-b+\left(b^{2}-4 c\right)\right]^{0.5}
$$

that is the piling-up due to the momentum flux equilibrium. Besides the mass balance produce another piling-up contribution:

$$
\delta_{q}=q^{2} B_{e q} /\left(f^{2}\left|R_{c}\right|^{10 / 3}\right)
$$

where $f$ is the friction factor and $q$ the flow rate. Terms $b, c$ and $B_{e q}$ in equations (2) and (3) depend on several parameters: position of the breaking point $\left(x_{b}\right)$, breaking depth $\left(d_{b}\right)$, breakwater freeboard $\left(R_{c}\right)$, incident significant wave height $\left(H_{m 0 i}\right)$, transmission coefficient $\left(K_{t}\right)$, breakwater geometry.

Many literature works characterize the efficiency of emerged/submerged breakwaters (e.g. Pilarczyk 2003, Burcharth et al. 2007), in particular, some of them are focalised on the hydrodynamics (circulation system, vorticity, etc.), sediment transport and water quality (see, for example, Lorenzoni et al. 2005), many laboratory studies have been dedicated to evaluate the transmitted and reflected wave heights, run-up, set-up, overtopping, etc. of breakwaters (see, for example, Van der Meer 2005) and some studies characterize the shoreline long-term response in the presence of detached barriers (e.g. Larson et al. 1997). The present work is, instead, focused on the analysis of the -storm features correlated to the short-term evolution of the cross-shore seabed profile of a protected beach, since few studies have been done on this topic. In particular, a behaviour analysis of the traditional rubble-mound breakwaters, comparing hydrodynamic and morphodynamic features of emerged or submerged types, in cross-shore conditions (considering in the absence of longshore contributions), are described.

The main aim is to characterize the short-term morphodynamic evolution of the cross-shore profile of the whole protected beach under various wave conditions and for the different breakwater configurations, analyzing the main strengths and weaknesses of the emerged/submerged structure types and the best breakwater geometry (in particular, section features like submergence, berm width, lateral slopes and distance from the shoreline), in order to best preserve the emerged beach.

To better investigate the dynamics of mentioned mechanisms and try solutions that minimize their negative impacts onto the native beach, the present analysis has been performed on the basis of a dedicated campaign of physical model tests, reproducing a protected beach described in the following.

\section{CONDITIONS AND PROBLEMS OF THE BEACH OF GABICCE MARE (ITALY)}

The mentioned experiments are part of a more general study on the coastal defence of the beach of Gabicce Mare (Italy). The beach is located on the central Adriatic coast, at the extremely North part of the Marches Region, very close to the famous Romagna beaches, at $15 \mathrm{~km}$ from the well known Rimini.

The beach is about $1.8 \mathrm{~km}$ long and it is completely confined between the jetties of the Port of Cattolica, at NorthWest, and the promontory of the Colle San Bartolo, at SouthEast (see Fig. 2, left panel). It is mostly a sandy beach, but, on the Eastern part, in correspondence of the beginning of the promontory, the prevailing sediments progressively become gravels and cobbles.

Over the last century, coastal defences were built, especially in "emergency condition", with focus on the sandy beach, then extended to the promontory protection. Nowadays this results in a very disordered distribution of rubble-mound emerged breakwaters, without a general homogeneity (some barriers aligned, other oblique, at V/L-shapes, at different distances from the shoreline, etc.). More than these aesthetical problems, also practical and environmental problems remained unsolved, like: erosion of some beach parts, reduced circulation, mud and seaweed deposit in the nearshore protected zone.

Technicians of local authorities (region and municipality) are studying solutions to solve the beach problems. The preliminary design (Autorità di bacino della Regione Marche 2005) is to transfer the present breakwaters onto a new planimetric arrangement, with a more offshore realigned position (Fig. 2 , right panel) and to substitute the present emerged rubble-mound defences with submerged ones. 

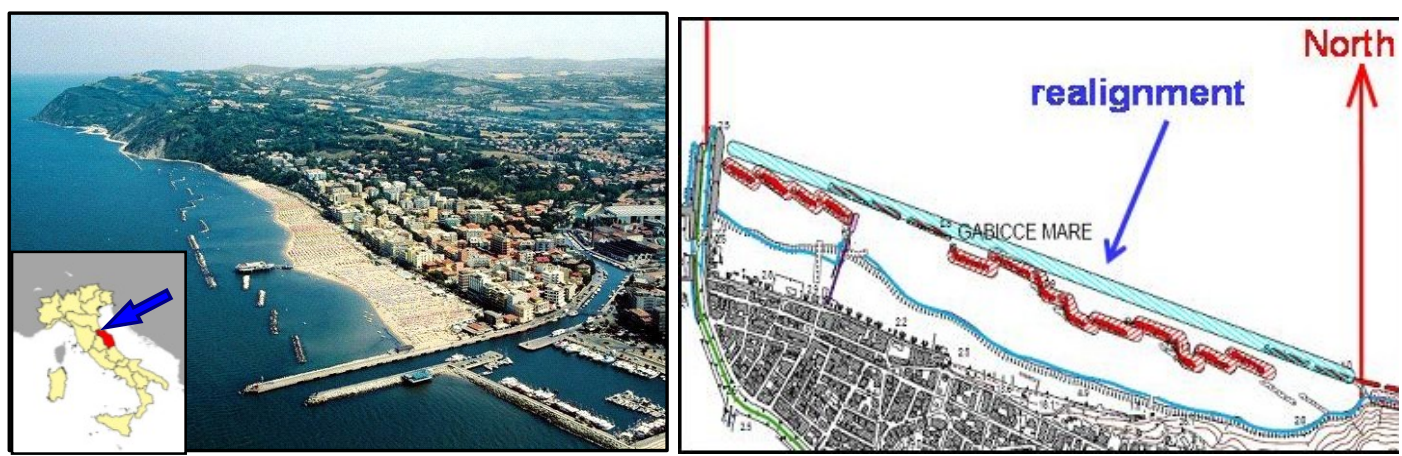

Figure 2. The beach of Gabicce Mare (left panel) and the plan of preliminary coastal design (right panel).

For this part of the general study the attention is addressed to search the optimal geometry of the requested breakwaters (in terms of submergence, berm width, lateral slopes, length and especially orientation, position and distance from the shoreline) able to best preserve the emerged beach and to best understand the influence of different barriers on the morphodynamic beach evolution.

\section{THE EXPERIMENTAL TESTS}

The campaign of the experimental tests was performed in the 2D wave flume of the Laboratorio di Idraulica of the Università Politecnica delle Marche (Ancona, Italy), as described in Lorenzoni et al. (2009). This laboratory hosts a wave flume, equipped with a wavemaker, for 2D maritime physical models at reduced scale. The inside dimensions of the flume are: length $50 \mathrm{~m}$, width $1 \mathrm{~m}$, height from the bottom $1.3 \mathrm{~m}$. The flume can work with a maximum water depth of $1 \mathrm{~m}$. The lateral walls of the flume, in which steel vertical rods and wide glass windows alternate for both sides of the central $36 \mathrm{~m}$, enable to observe, to photograph or to video-record the flow and the morphological evolution from the lateral sides. The wave generation system, provided by Wallingford (UK), is made of a vertical paddle with a piston-type motion (with max run of $1 \mathrm{~m}$ ) activated by an electrical engine with power of $4 \mathrm{~kW}$.

The model set in the wave flume represented a cross-shore section of the protected sandy beach of Gabicce Mare. The simulated rubble-mound breakwater was moved from pillar to post when a change of configuration occurred. The cross-shore section of the beach chosen to be tested is one of the most significant, in fact it is characterized by the protection breakwater closest to the shoreline, with the more extended salient, so its beach profile is the most critical to support and to absorb eventual changes of position or of section geometry of the front barrier. Fig. 3 (left panel) shows the results of a multibeam bathymetric survey of the beach (in September 2008), where an offshore area, with some of the natural aligned submerged rocks is evident and also indicated as the tested section. Its profile was first partially rectified (to make a simpler model realization) then reproduced in the described flume as a $2 \mathrm{D}$ (in the vertical plane) movable-bed model with a geometrical reduced scale of 1:20 (see Fig. 3, right panel, and Fig. 4 for the flume/model sketch). Froude similarity was used for the hydrodynamics. The sand of the movable-bed model $\left(D_{50}\right.$ of about $\left.0.13 \mathrm{~mm}\right)$ was chosen as suitable to simulate the natural sand of the prototype beach $\left(D_{50}\right.$ of about $\left.0.2 \mathrm{~mm}\right)$, following the Dean criterion.
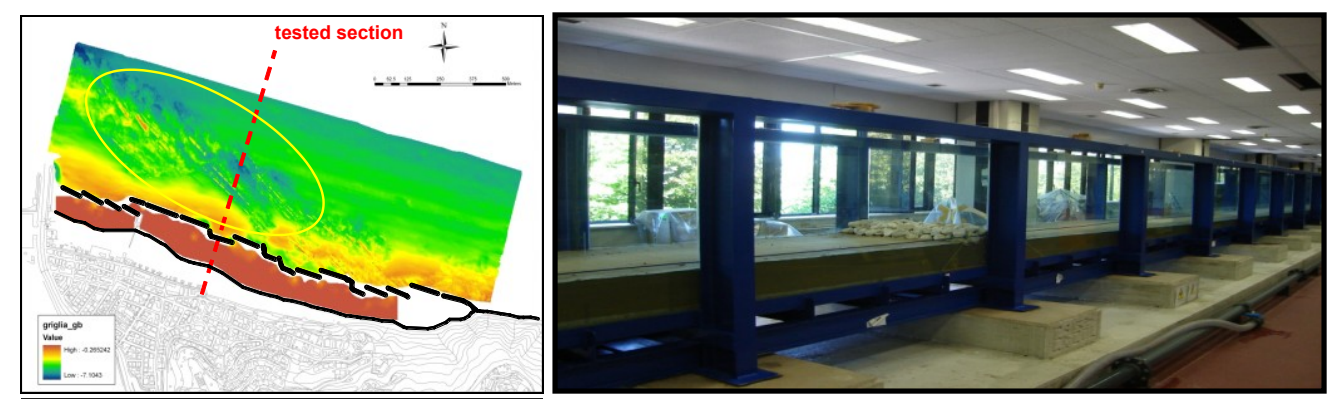

Figure 3. Bathymetric survey map (left panel) and the movable-bed physical model in the flume (right panel). 


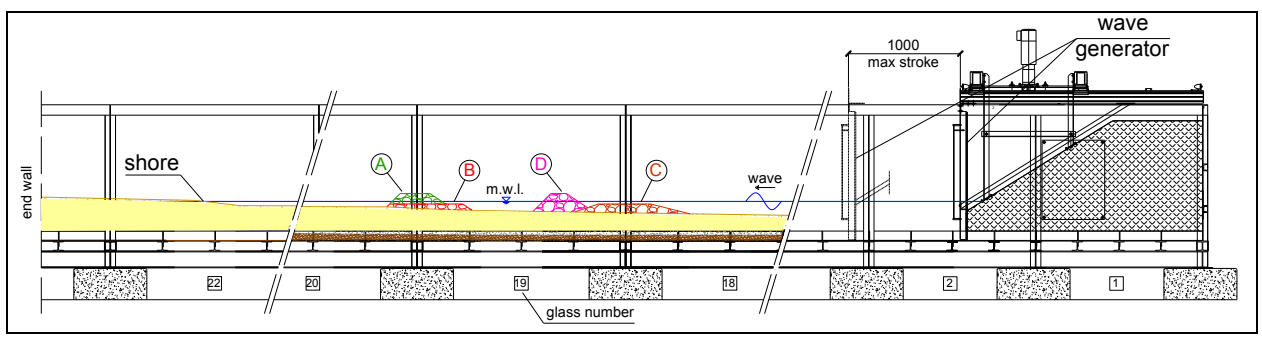

Figure 4. Sketch of the flume between the simulated shoreline (left) and the wave generator (right), with the breakwater positions area (middle).

Three emerged (A, D, E) and three submerged (B, C, F) breakwater configurations, different for cross-section geometry and/or position, were reproduced. Also a configuration with no structure (G), simulating a planar free beach, was modelled, as a benchmark case for the other tested structure configurations. They are shown in section detail of Fig. 5, with different colours.

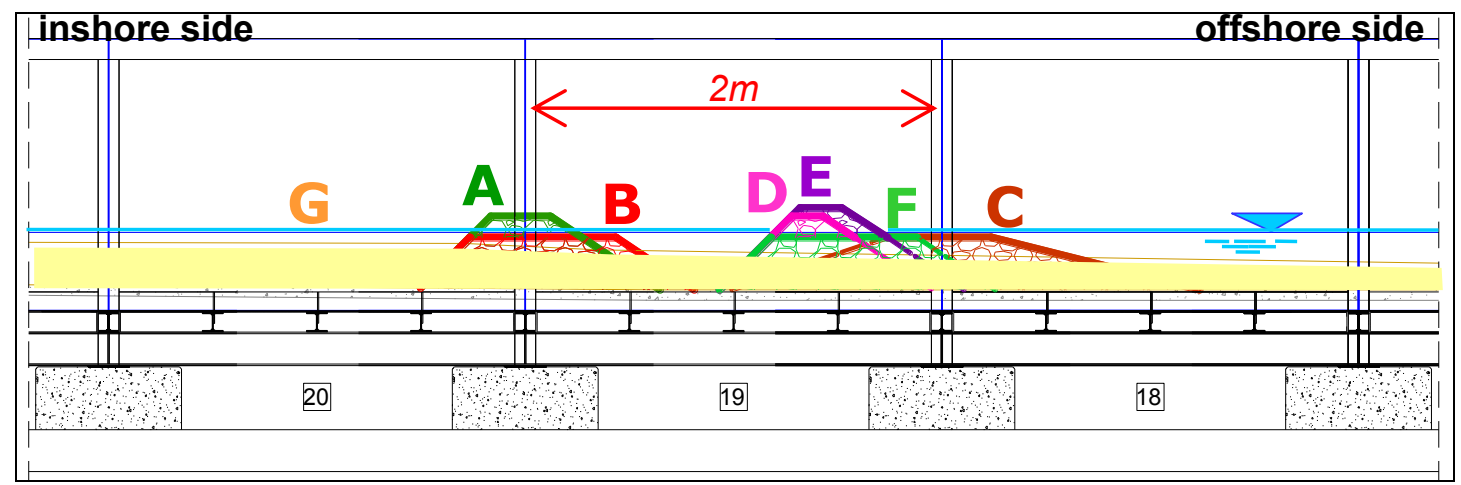

Figure 5. Sketch of the section detail of the flume in correspondence of the positions of all the tested breakwater configurations.

Both regular and irregular waves were forced. The most important wave attacks reproduced in the flume were three extreme events (named OS1, OS2 and OS3) that simulated typical sea storms effectively observed in the Adriatic Sea, actually occurred in 1999, 2002 and 2004, respectively (ISPRA 2012). In the nearshore the waves were directed enough orthogonally to the analyzed beach. Their peak wave heights were of about $5 \mathrm{~m}$ in prototype, that are very severe for the Adriatic Sea. Every storm was reproduced maintaining a constant mean water level to simulate the time-averaged value of the related storm-surge superelevation $(2 \mathrm{~cm}, 3.5 \mathrm{~cm}$ and $2 \mathrm{~cm}$, in the model, respectively). The entire period of each tested storm was divided into four different phases, that were reproduced, in the flume, separately and in a sequence, by a constant JONSWAP wave spectra to simulate the complete storm. For example, the timeseries of the sea storm OS1 is shown in Fig. 6 with the sketches of the relative offshore and nearshore wave data. Input values of wave conditions of each phase of the tested storms are listed in Table 1 for the prototype depth of $7.48 \mathrm{~m}$ (corresponding to the model depth at the paddle).

Water level measurements were performed by means of 8 elettro-sensitive gauges, placed and fixed at different positions along the entire model profile from the wave generator to the structure model zone. The morphological evolution of the movable-bed profile during the tests was surveyed in view, without instruments, observing across the glassed side walls drawing on millimetered paper the profile, at that given moment, of the beach at both sides of the flume, then the mean value of these two measures (at both sides) has been computed and taken as the single sequence value along the model. The measures were done at the beginning and at every phase end of each tested wave attack.

Our analysis simply correlates the wave forcing with beach morphological changes. Further, we investigated: i) the beach response to wave attacks when emerged/ submerged breakwaters are used, ii) how both geometry and distance to shore of the barriers influence the erosion rate of the beach, iii) the overall beach morphology, iv) how the shoreline evolves in the short-term. Experimental data of the 
tests were evaluated and compared, enabling us to pinpoint what are the crucial parameters that must be taken into account for a proper breakwater section design, e.g. cross-shore positioning of a structure for optimal functioning, optimal berm width to minimize the shoreline retreat, etc.

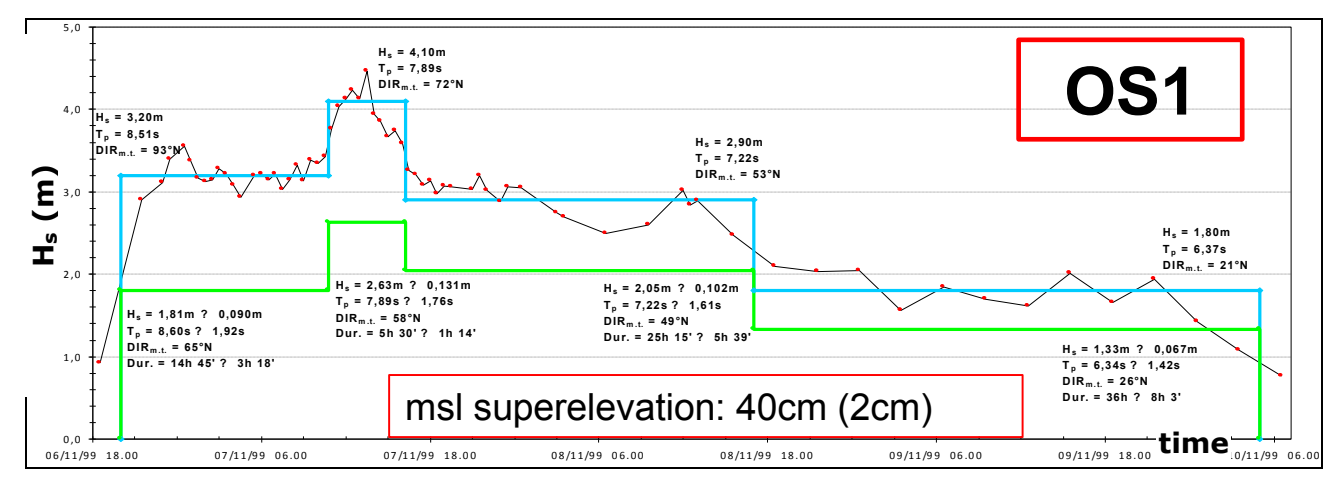

Figure 6. Timeseries of the tested sea storm OS1.

\begin{tabular}{|c|c|c|c|c|c|c|}
\hline \multicolumn{6}{|c|}{ Table 1. Characteristics of the reproduced sea storms at model scale. } \\
\hline Wave & Phase & Type & $\begin{array}{c}\text { Duration } \\
(\mathrm{hh}: \mathrm{mm})\end{array}$ & $\begin{array}{c}\mathrm{Hs} \\
(\mathrm{m})\end{array}$ & $\begin{array}{c}\mathrm{Tp} \\
(\mathrm{s})\end{array}$ & $\begin{array}{c}\mathrm{Ah} \\
(\mathrm{m})\end{array}$ \\
\hline OS1 & 1 & spectrum & $03: 18$ & 0.090 & 1.92 & 0.02 \\
\hline OS1 & 2 & spectrum & $01: 14$ & 0.131 & 1.76 & 0.02 \\
\hline OS1 & 3 & spectrum & $05: 39$ & 0.102 & 1.61 & 0.02 \\
\hline OS1 & 4 & spectrum & $08: 03$ & 0.067 & 1.42 & 0.02 \\
\hline OS2 & 1 & spectrum & $04: 05$ & 0.046 & 1.60 & 0.036 \\
\hline OS2 & 2 & spectrum & $04: 48$ & 0.058 & 1.90 & 0.036 \\
\hline OS2 & 3 & spectrum & $03: 18$ & 0.111 & 2.10 & 0.036 \\
\hline OS2 & 4 & spectrum & $13: 52$ & 0.047 & 1.85 & 0.036 \\
\hline OS3 & 1 & spectrum & $00: 27$ & 0.083 & 1.20 & 0.02 \\
\hline OS3 & 2 & spectrum & $00: 54$ & 0.135 & 1.92 & 0.02 \\
\hline OS3 & 3 & spectrum & $04: 15$ & 0.083 & 1.62 & 0.02 \\
\hline OS3 & 4 & spectrum & $10: 51$ & 0.063 & 1.36 & 0.02 \\
\hline
\end{tabular}

Here below some results and comparisons on hydro-morphodynamics of the tests are described.

\section{TEST RESULTS}

Because of the lack of studies on the relationship between wave transmission and shoreline response, here the wave transmission problems and the cross-shore profile morphodynamic evolution are separately discussed.

\section{Hydrodynamics}

The cross-shore profiles of the water levels collected along the model, are first analyzed.

Fig. 7 shows the wave height trends, due to some representative phases, for example, for both emerged (left panel) and submerged (right panel) breakwater configurations. They are plotted together with the initial beach profile and with the same trend for configuration G, i.e. the structure-free configuration. Each coloured line refers to a single configuration.

For the both structure types, emerged and submerged, very evident abrupt height decays over the breakwaters can be observed. The different breakwater configurations of the same type, with different distance of the barriers from the shore, seem to provide similar dissipations. The wave reduction, as obviously expected, is greater for emerged than for the submerged structures. Obviously, again, the structure-free configuration $(\mathrm{G})$ induces less wave height reduction than the other cases. Table 2 shows the transmission coefficient $K_{t}=H_{t} / H_{i}$ for all the structure configurations and the tested storm phases of the wave attacks, where $H_{i}$ and $H_{t}$ are the significant wave heights incident and transmitted inshore of the barrier, respectively. These wave heights were chosen as the values measured just shoreward and just seaward of the breakwaters, so they were measured at different gauges, among the various structure configurations, depending from each breakwater position and from the closest available instrument (the same reference gauges were used only for configuration pairs A and B, .C and F, D and E). 

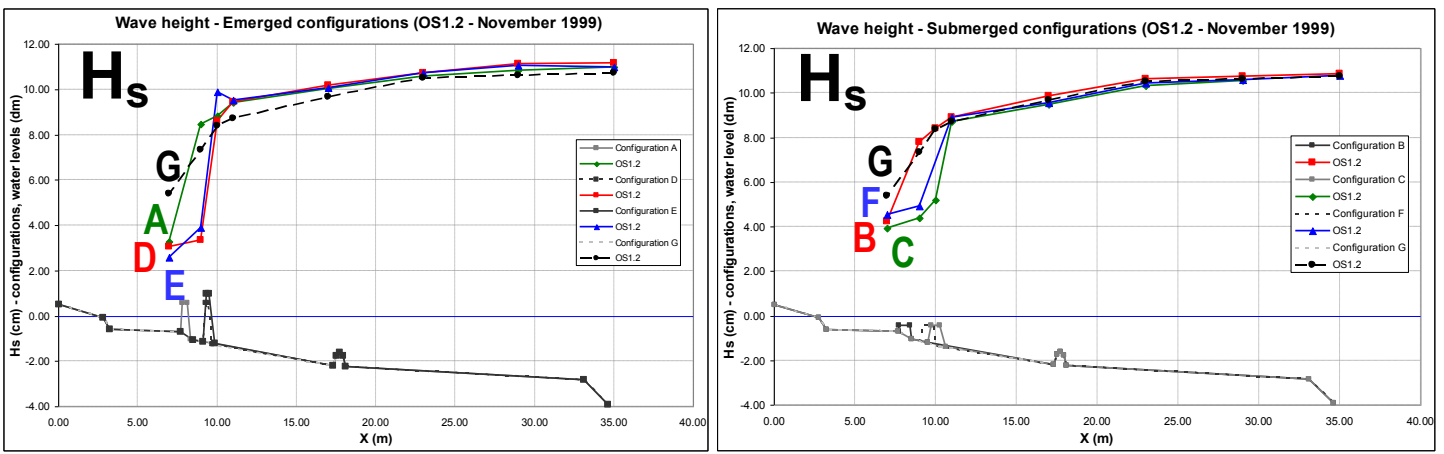

Figure 7. Wave height cross-shore profile for the emerged (left panel) and the submerged configurations (right panel), with the profile of the structure-free configuration.

Table 2. Transmission coefficient $\mathrm{K}_{\mathrm{t}}$ for the breakwater configurations and the tested wave attacks

\begin{tabular}{|c|c|c|c|c|c|c|c|c|c|c|c|c|}
\hline Config. & OS1.1 & OS1.2 & OS1.3 & OS1.4 & OS2.1 & OS2.2 & OS2.3 & OS2.4 & OS 3.1 & OS 3.2 & OS3.3 & OS 3.4 \\
\hline A & 0.355 & 0.353 & 0.332 & 0.302 & 0.366 & 0.461 & 0.428 & 0.439 & 0.266 & 0.309 & 0.321 & 0.311 \\
\hline B & 0.551 & 0.544 & 0.558 & 0.541 & 0.780 & 0.698 & 0.543 & 0.826 & 0.454 & 0.510 & 0.523 & 0.581 \\
\hline C & 0.552 & 0.503 & 0.526 & 0.570 & 0.748 & 0.753 & 0.638 & 0.865 & 0.446 & 0.699 & 0.540 & 0.600 \\
\hline D & 0.311 & 0.359 & 0.390 & 0.411 & 0.480 & 0.674 & 0.594 & 0.536 & 0.670 & 0.435 & 0.459 & 0.497 \\
\hline E & 0.413 & 0.394 & 0.494 & 0.628 & 0.395 & 0.373 & 0.313 & 0.496 & 0.379 & 0.322 & 0.387 & 0.502 \\
\hline F & 0.588 & 0.555 & 0.547 & 0.703 & 0.827 & 0.802 & 0.674 & 0.902 & 0.555 & 0.529 & 0.544 & 0.644 \\
\hline
\end{tabular}

For the example case shown in Fig. 7, wave reductions, along the entire profile, of more than $70 \%$ per-cent for the emerged configurations (A: 70\%, D: 73\%, E: 77\%) and of about $60 \%$ per-cent for the submerged ones (B: 61\%, C: 63\%, F: 58\%) were observed. But also the configuration G, with no structures, induces a global wave height dissipation of about $50 \%$ per-cent., mostly due to wave shoaling, seabed roughness and porosity, viscosity (internal friction), etc. Thus, the net contribution, in terms of dissipation, of the breakwaters for each configuration can be estimated as the difference between the one of the defended configurations (A to F) minus the dissipation of the structure-free configuration (G). Such a difference, i.e. the "net wave damping" for the entire model, can be easily evaluated to be more than $20 \%$ for the emerged breakwater configurations (A: $20 \%$, D: $23 \%$, E: $27 \%$ ) and of about $10 \%$ for the submerged ones (B: $11 \%, \mathrm{C}: 13 \%, \mathrm{~F}: 8 \%$ ).

A similar analysis for the mean water levels, Fig. 8, shows the cross-shore distributions of the mean level measured for all the tested configurations (emerged structures in the left panel and submerged in the right panel) for some of the analyzed wave conditions. Like in the previous cases, they are plotted together with the initial beach profile and with the structure-free configuration $(\mathrm{G})$ distribution.
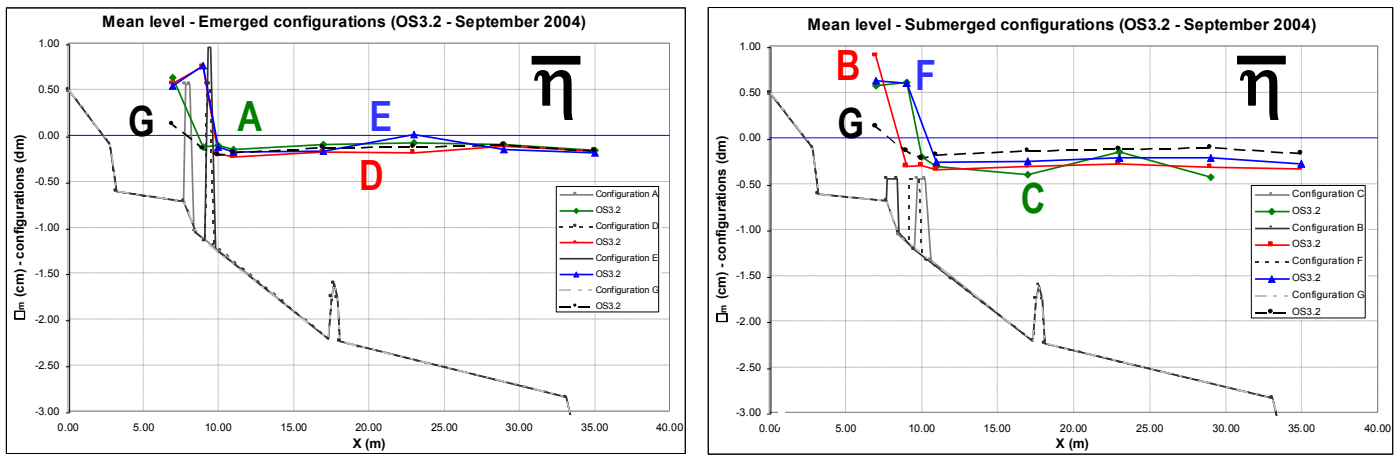

Figure 8. Mean water levels induced by emerged (left panel) and submerged (right panel) breakwaters.

The analysis of the mean water levels reveals that, beyond the large wave energy reductions, also evident are the level growths (piling-ups) with respect to the still water level, especially for the submerged breakwaters. In particular, for the cases reported in Fig. 8, OS1 and OS2, the ratios between 
the wave piling-up and the incident wave height offshore of the structure are of less than $10 \%$ for both the emerged and the submerged breakwaters (A: 5\%, B: $8 \%, \mathrm{C}: 6 \%, \mathrm{D}: 5 \%, \mathrm{E}: 4 \%, \mathrm{~F}: 6 \%$ ), but with some large values for the submerged ones. The structure-free configuration $(G)$ also induces a mean level growth. The same ratio, for this case, results of about $1 \%$. So evaluating the "net" values of pilingup for the structure configurations, the behaviour difference between emerged and submerged structures becomes a little more evident: about $4 \%$ for the emerged (A: $4 \%$, D: $4 \%$, E: $3 \%$ ) and about $6 \%$ for the submerged cases (B: 7\%, C: 5\%, F: 5\%).

There are many variables/parameters related to the hydrodynamic/morphodynamic evolution of beaches protected by low-crested breakwaters. In the case of $2 \mathrm{D}$-experiments and for fixied structure section, only the transmission coefficient $K_{t}$, the distance from the shoreline and the wave features vary, hence these parameters are first analyzed.

The plot of $K_{t}$, with the wave steepness $H / L$ for all the structure configurations and wave conditions (see Fig. 9), shows that for the emerged configurations it is, in average, of about $43 \%$, while for the submerged configurations it is of about $62 \%$. All the submerged configurations display very similar behaviours: their data is concentrated in a quite narrow band. The regression indexes (indicating the fitting goodness, i.e. how much the regression line interpolates the data) for the submerged configurations $(\mathrm{B}, \mathrm{C}$ and $\mathrm{F}$ ) range between 0.81 and 0.91 and the global one is of about 0.83 . While the data of the emerged configurations (A, D and E) are much more scattered and their regression indexes, for the three configurations, vary between 0.15 and 0.74 and the global one is of about 0.39 .

Comparing structures of the same type and similar dimensions but with different positions (onshore/offshore), for example A and D for the emerged, B and F for the submerged, shows that onshore configurations are able to provide smaller $K_{t}$ values than those provided by the offshore ones.

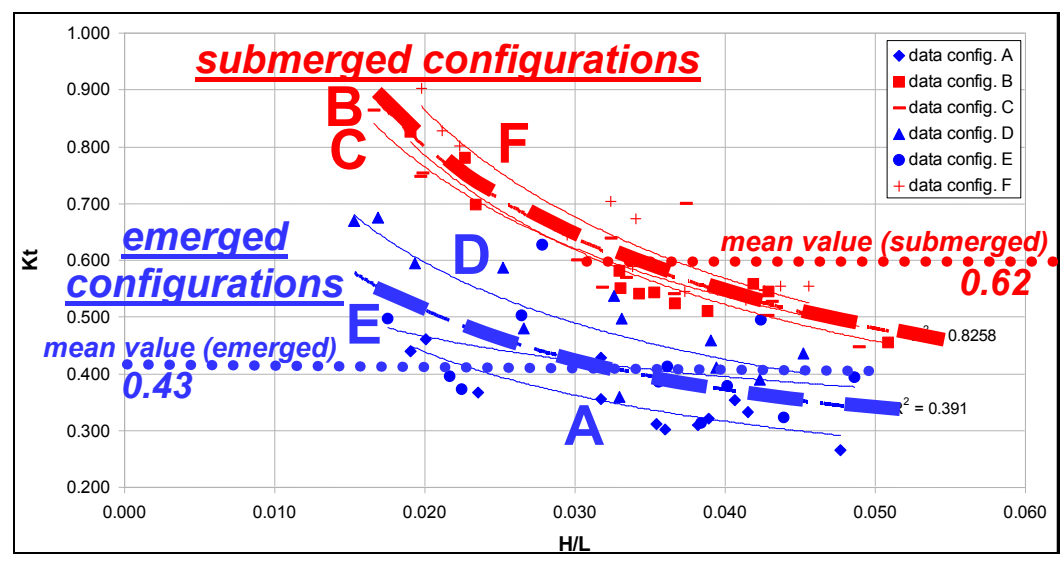

Figure 9. Dependence of $K_{t}$, for all the structure configurations, on the wave steepness $H / L$ of all the analyzed wave conditions (phases of the tested storms).

Comparisons of experimental data with some theoretical laws valid for low-crested coastal rubblemound structures were also tried. For this analysis we considered Van der Meer (1990), Van der Meer et al. (2005) and Buccino and Calabrese (2007), being the latter one suitable just for submerged structures (in the following they are indicated by VdM'90, VdM'05 and BC'07, respectively). For emerged configurations (Fig. 10, left panel) data are very scattered and no good agreement was found. On the opposite the BC'07's theoretical line fits well the (more concentrated) experimental data of the submerged configurations (Fig. 10, right panel). The regression indexes of the considered theoretical laws are lower than those of the curve giving the experimental data, such as: 0.09 for VdM' 90 and 0.18 for VdM'05 for the emerged structures, while they are 0.75 for VdM'90, 0.02 for VdM'05 and 0.91 for BC'07 for the submerged configuration applications.

By definition, wave transmission and wave damping, are strictly connected: at the same positions, they are complementary to 1 . So, considering the previously introduced "net wave damping" of different structure configurations, we could also introduce a, so called, "net wave transmission coefficient" directly correspondent to the relative "net wave damping". 

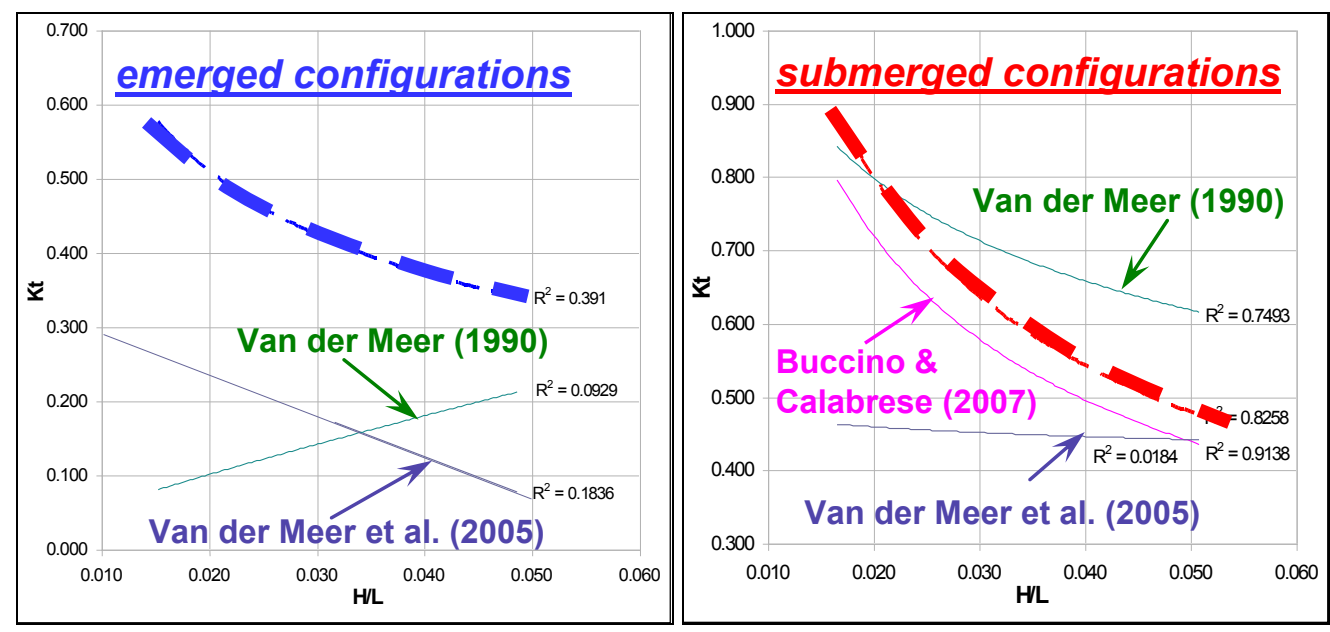

Figure 10. Theoretical laws for $K_{t}$, fitted onto the experimental data of $K_{t}$, for emerged (left panel) and submerged (right panel) structure configurations.

We call: $\alpha_{\text {structure }}, \alpha_{\text {free }}$ and $\alpha_{\text {net }}$ the wave dampings, referring to same positions of corresponding transmission coefficient, for protected, unprotected configurations and the corresponding "net" value, respectively; $K_{t, \text { structure }}, K_{t, f r e e}$ and $K_{t, n e t}$ the transmission coefficients for protected, unprotected beaches and the corresponding "net" value, respectively. Remembering the complementary relationships:

$$
\alpha_{\text {structure }}=1-K_{t, \text { structure }} \quad \alpha_{\text {free }}=1-K_{t, \text { free }} \quad \alpha_{\text {net }}=1-K_{t, \text { net }}
$$

and the introduced difference for the "net wave damping":

$$
\alpha_{\text {net }}=\alpha_{\text {structure }}-\alpha_{\text {free }} \text {; }
$$

the expression of the "net wave transmission coefficient" can be easily found:

$$
K_{t, \text { net }}=1-K_{t, \text { free }}+K_{t, \text { structure }}
$$

Insertion of the evaluated experimental "net transmission coefficients" in the previous diagrams $\left(K_{t}\right.$, versus $H / L$ ) is easily made (see Fig. 11). Comparing these "net" values with the mentioned theoretical laws supports that no interesting agreements for the emerged configurations exists, while, with some surprise, a very strict correspondence of submerged data with the VdM'90 law was obtained!
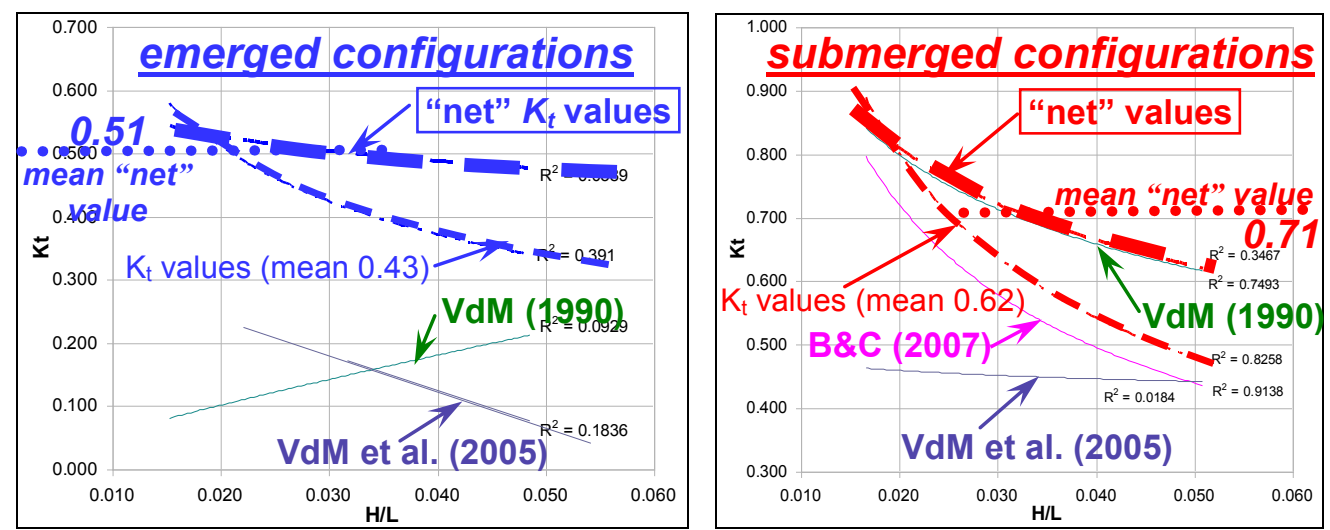

Figure 11. Dependence of "net" $K_{t}$, on $\mathrm{H} / \mathrm{L}$ for emerged (left panel) and submerged (right p.) configurations.

Mean values of the "net" $K_{t}$, of about $51 \%$ for the emerged and of about $71 \%$ for the submerged configurations were obtained (higher than the $K_{t}$ values). Again, the submerged configurations showed more similar behaviours than the emerged ones, but the regression indexes of the fitting curves of their 
experimental data, are very low: just about 0.04 for the global emerged configurations (A, D and E) and about 0.35 for the submerged ones $(\mathrm{B}, \mathrm{C}$ and $\mathrm{F})$.

The propagation of long waves over submerged breakwaters (see Fig. 12, left panel) results in a wide number of little shorter waves. Hence, the transformed wave spectrum shows a large energy reduction and a translation towards higher frequencies, as indicated by Battjes and Beji (1991). For the described tests, an example on submerged configurations $\mathrm{B}$ and $\mathrm{C}$ is shown in Fig. 12 (right panel). A large energy decay and its spectral reduction can be observed, but with a very low frequency dispersion. This is probably due to relatively short waves tested, they seem simply wind short waves, so breaking dissipation, in shallow waters, dominates and spectral transfers towards higher frequencies reduce.
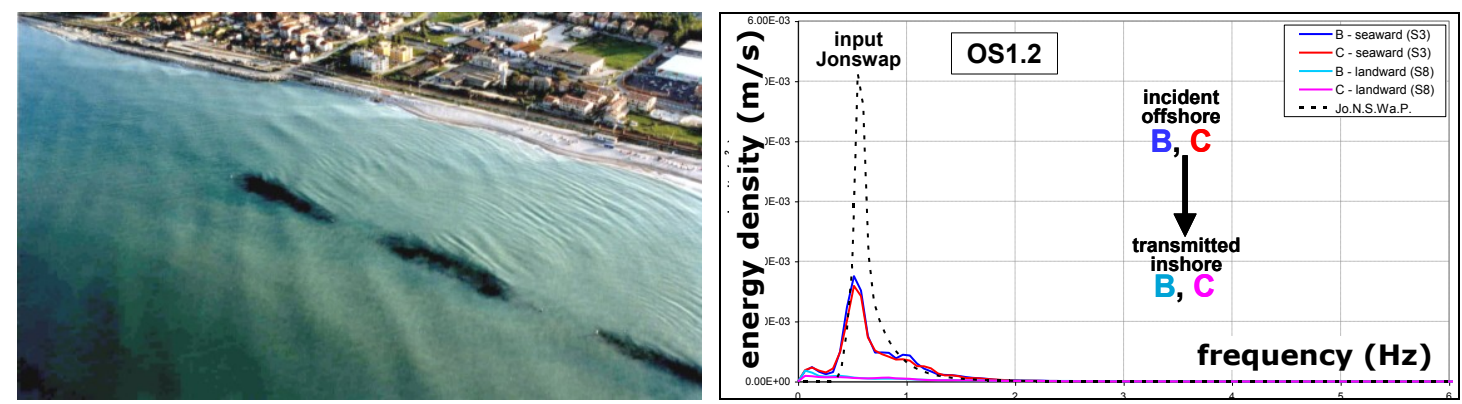

Figure 12. Propagation of long waves (left panel) and tested spectra (right panel) over submerged rubblemound breakwaters.

\section{Morphodynamics}

Some obtained morphodynamic results on cross-shore beach profile evolution are here discussed. During each wave attack of the four mentioned phases of the three simulated storms, the beach profile gradually modified. Progressive shoreline retreats, the steepening of the front scarp at the shore, the progressive deepening of local erosion at the toes (more at offshore) of the defence structure and the formation and growth of emerged berms in the swash zone can be observed (see Fig. 13, for example).

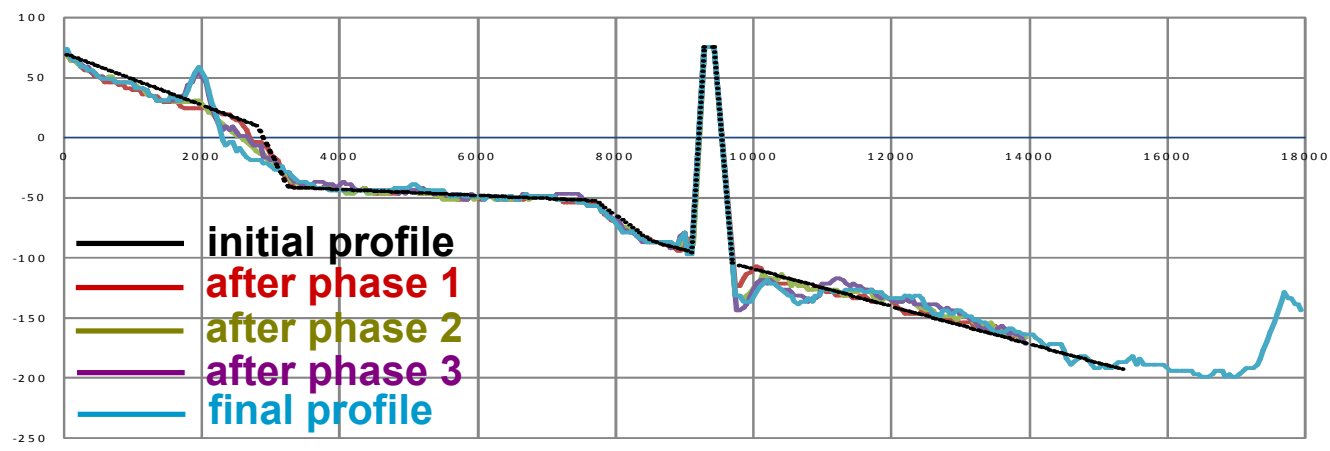

Figure 13. Bed profile evolution after each phase of the sea storm OS3 for the structure configuration D.

Some global results can be found by comparing the final bed profiles for the configurations with the same structure types at different positions, emerged (Fig. 14, top panel) and submerged (Fig. 14, bottom panel), in both cases also with the structure-free configuration $(\mathrm{G})$,.

The structure-free $(\mathrm{G})$ and the submerged configurations $(\mathrm{B}, \mathrm{C}$ and $\mathrm{F})$ induce very similar shoreline retreats. Emerged configurations of similar dimensions (A, D) show similar retreats, smaller than that forced by the structure-free configuration $(\mathrm{G})$ and larger than that of the largest configuration $(\mathrm{E})$.

Comparison of the final bed profiles for the configurations of different structure types at the same positions, onshore (Fig. 15, top panel) and offshore (Fig. 15, bottom panel), also with the structure-free configuration $(\mathrm{G})$, reveals, as obviously expected, that the emerged breakwaters induce the smallest shoreline retreats.

The graphs of Fig. 16 show the chronological shoreline retreat, of all the configurations for all the tested storm attacks. The structure-free $(G)$ and the submerged configurations (B, C and F) display 
similar retreats, larger than those provided by the emerged ones (A, D and E). This comparative behaviour is more evident for the wave attack OS2.

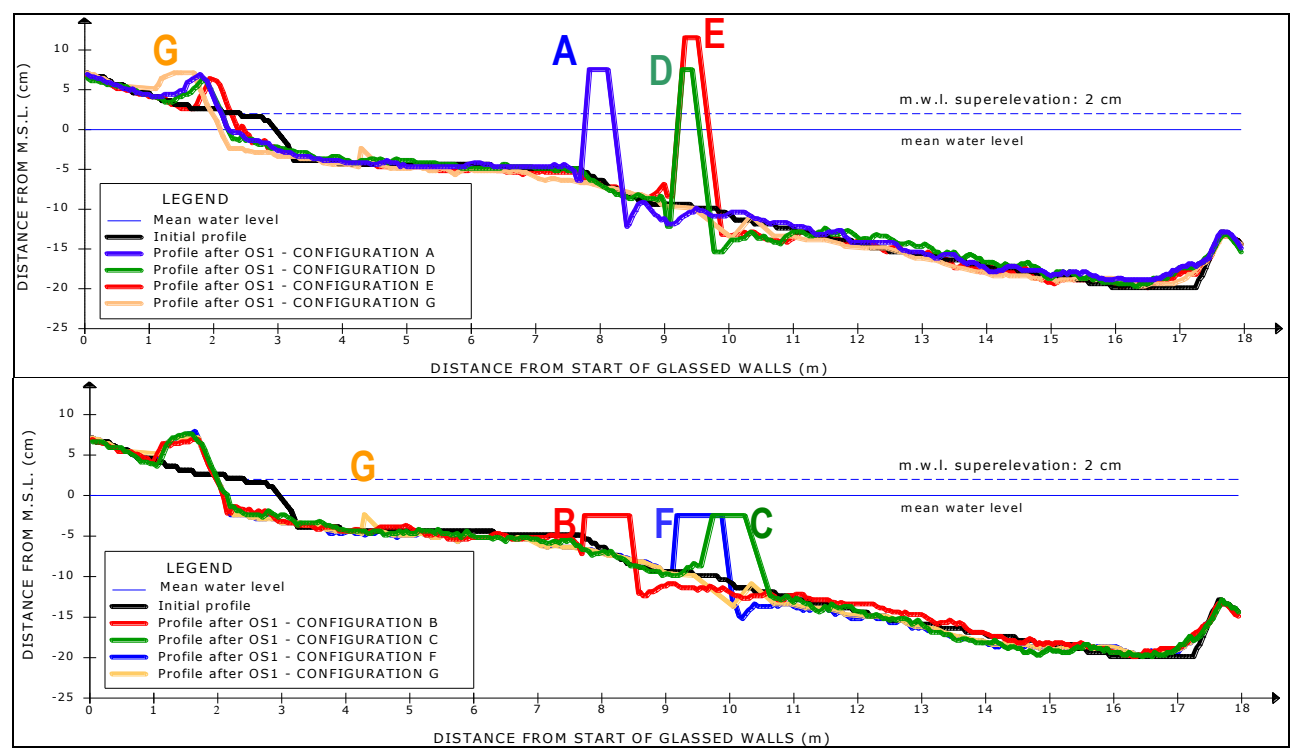

Figure 14. Final bed profiles for the structure-free configuration (G) and for the structure configurations of the same type at different positions, emerged (top panel) and submerged (bottom panel).

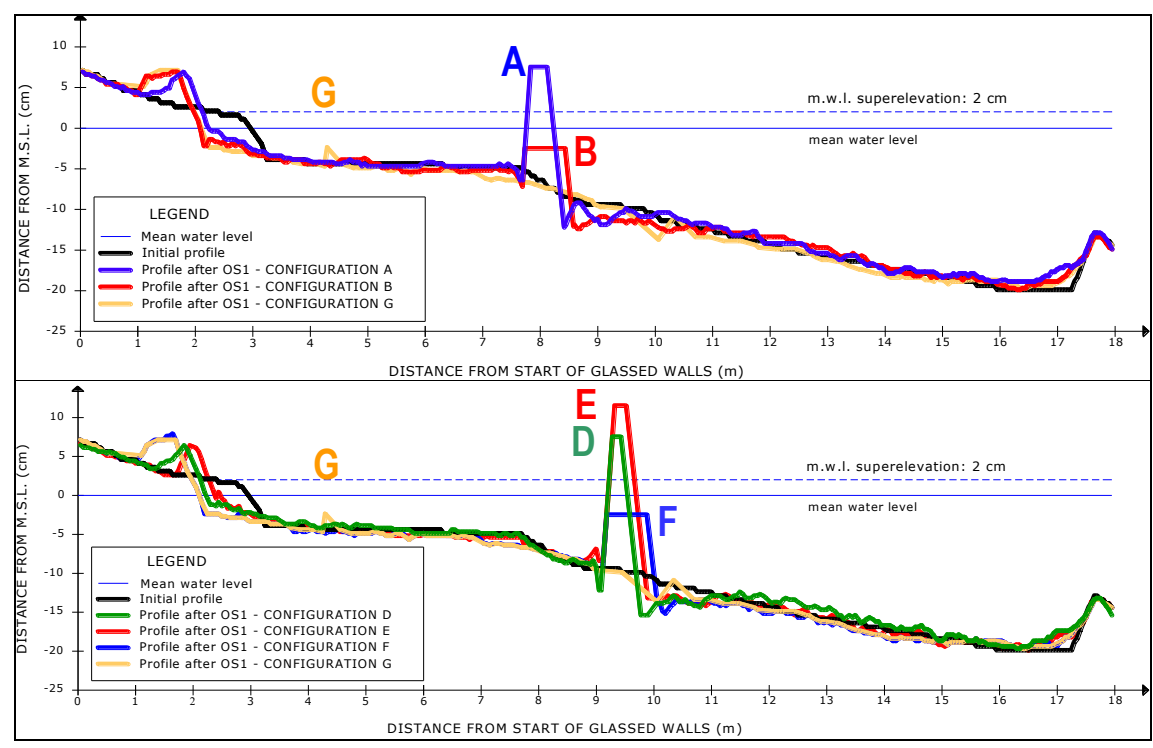

Figure 15. Final bed profiles for the structure-free configuration (G) and for the structure configurations of different type at the same positions, onshore (top panel) and offshore (bottom panel).

A comparison of the beach profiles for the submerged configurations $\mathrm{B}$ and $\mathrm{C}$ with the results of numerical simulations performed by means of the SBEACH model (Larson and Kraus 1989) have been done. The code estimates the amount of energy dissipated by waves during the shoreward propagation process including both breaking and non-breaking waves; while the evolution of the bottom profile is obtained by the mass conservation law. The results (see Fig. 17) show similar shoreline retreats, though the profile shapes (formation of emerged berm, local erosion near the structure toes) are very different. The morphodynamic mechanisms for the experimental tests in the flume are certainly affected by the features of the movable-bed material used to reproduce the prototype sand in the model. 


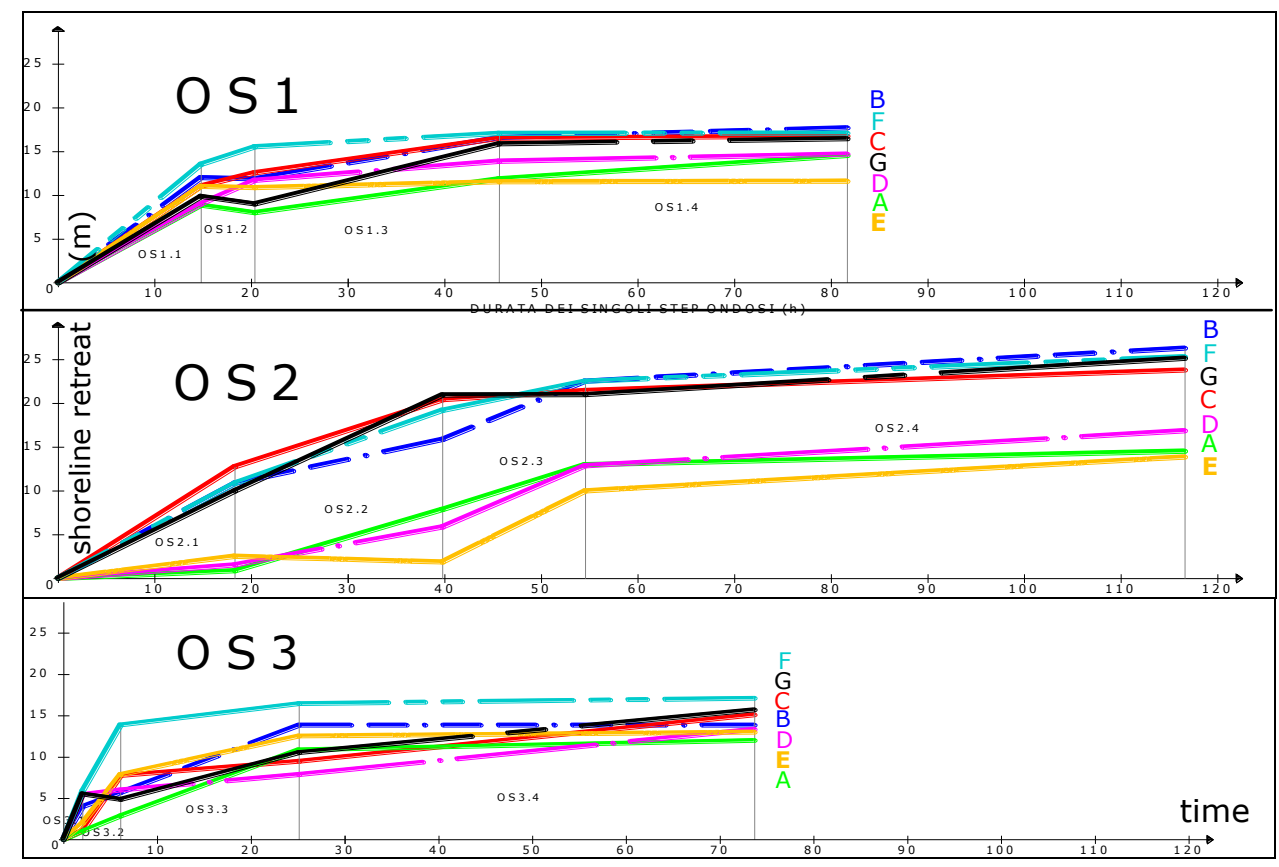

Figure 16. Chronological-shoreline retreat for all the tested configurations and storm attacks.
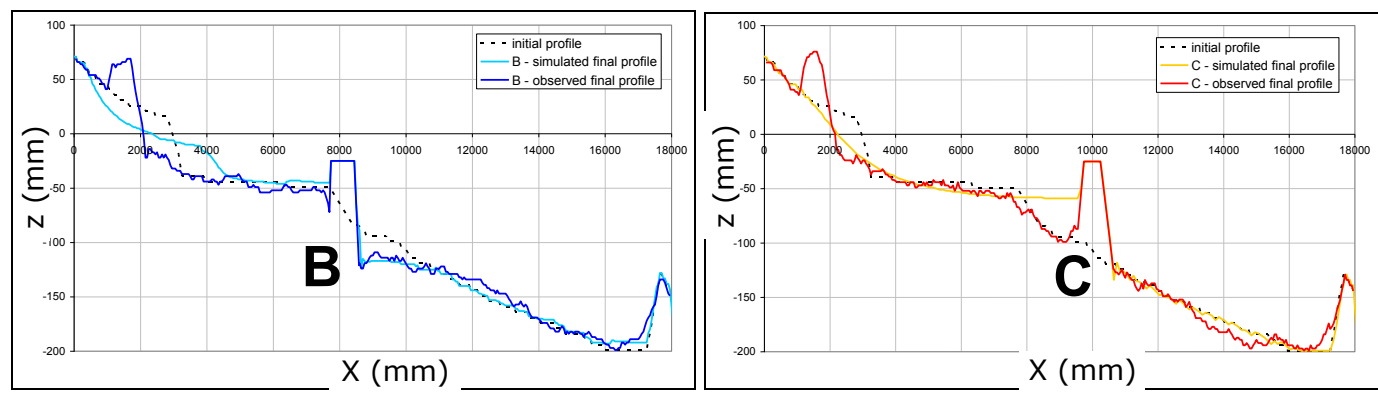

Figure 17. Beach profiles obtained from experimental tests and from numerical simulations for submerged configurations B (left panel) and C (right panel).

To further analyze the obtained results, the morphodynamic problems have been studied in more detail. Many studies were devoted to the morphodynamic evolution of unprotected cross-shore beach profiles. They highlighted some physical factors or dimensionless parameters, that are, usually, introduced for the general prediction/characterization of the beach profile type as modified by the wave action. A main distinction is made between "normal profile" and "storm profile" to identify the beach shape features in summer (with emerged berm formation in the swash zone) and in winter (with submerged bar generation in the surf zone), respectively. For example, Kraus's graph predicts the beach behaviour by relating the wave steepness in deep water on a parameter that contains wave and sand features (Kraus 1992). The experimental data have been plotted in the Kraus graph (evaluating the deep water wave height $H_{0}$ from the value measured inshore of the breakwater by a de-shoaling procedure on a free planar fictitious beach). Such data suggest the evolution of normal-type summer profiles (see Fig. 18), like the results of the experimental model tests.

About morphodynamics of protected beaches, few studies were available. Here some attempts were made to look for a relationships between breakwater distance from shore and shoreline change for the different tested conditions. Data sometime scattered were obtained, but also some partially satisfying agreements were found. The results of erosion velocity $(\Delta d / \Delta t)$ versus wave steepness $(H / L)$, for emerged/submerged configurations (left panel) and for some single separated configurations (right panel), useful to compare behaviours of their relative position along the model, are shown in Fig. 19. 


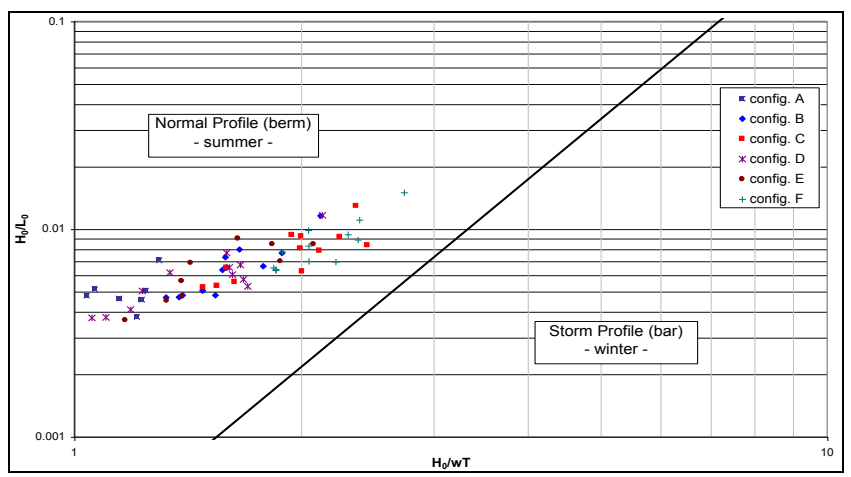

Figure 18. Beach profile type prediction by the Kraus's graph.

It seems clear that submerged configurations show larger retreat velocities than the emerged ones and differences increase for higher values of steepness (see Fig. 19, left panel). Analyzing the single configurations (see Fig. 19, right panel), the same behaviour of larger shoreline retreats are clearly shown for offshore configurations (D-emerged and F-submerged) with respect to the ones, of similar dimensions and typology (A-emerged and B-submerged), closer to the shore. Similar results, with just little differences, were found for erosion velocity $(\Delta d / \Delta t)$ versus relative height $(H / h)$, shown in Fig. 20, and also for erosion velocity $(\Delta d / \Delta t)$ versus incident wave celerity $(C)$, but there is no evidence of these tendencies, being the regression coefficients of lines very small.
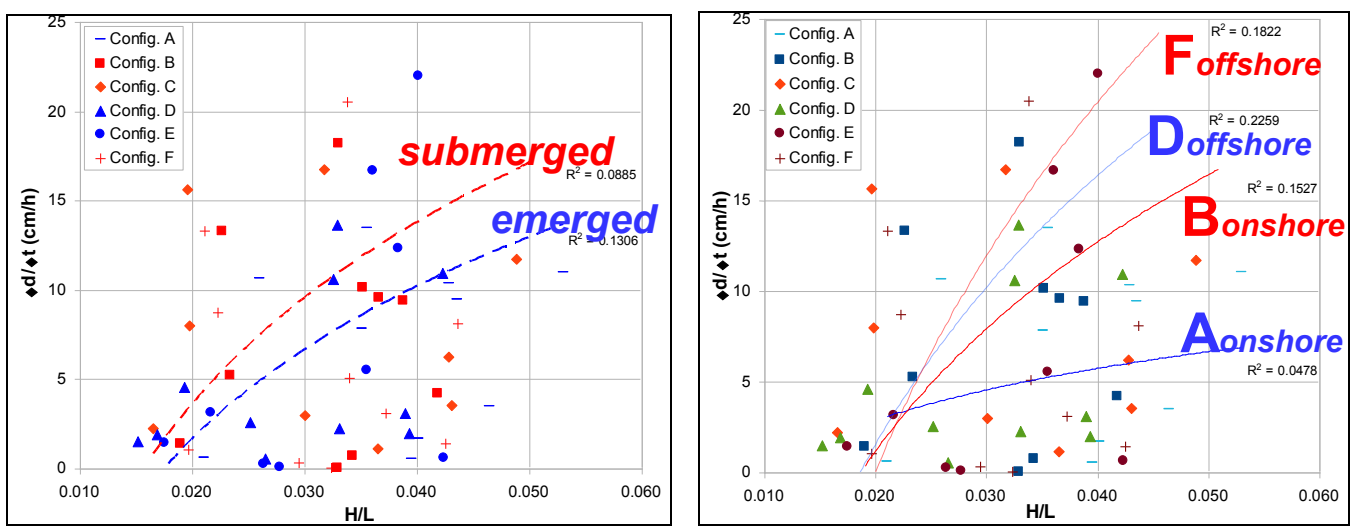

Figure 19. Erosion velocity related to wave steepness for all-emerged and all-submerged configurations (left panel) and for some single configurations separately-considered (right panel).
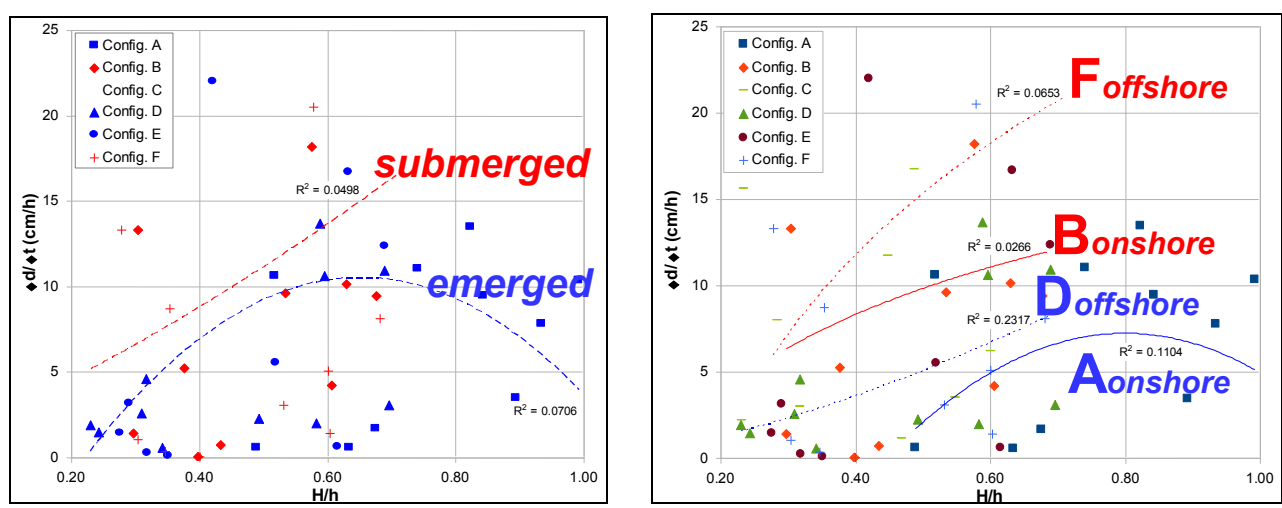

Figure 20. Erosion velocity on wave steepness of emerged/submerged (left) and single configurations (right) 
An approach based on the beach equilibrium profile properties was also been used to analyze profile data evolution of some submerged configurations. This method is common and suitable for longterm evolution analysis of natural beaches without any defence structure. For the studied short-term analysis of protected beach, the Gonzales et al. (1999) procedure, partially revised by Mancinelli et al. (2000), to consider the effect of wave transmission across the submerged obstacle, and the Convolution Method of Kriebel and Dean (1993), to predict the dynamic profile response during short-term storms (as a fraction, related to the storm duration, of the long-term potential one), were used. The application showed that, for the same wave conditions, smaller retreats were provided by the onshore configuration than the offshore one.

\section{CONCLUSIONS}

Analyzing all the obtained results in the 2D wave flume experiments, it could just conclude that the tested models of emerged and submerged rubble-mound breakwaters, showed the following results:

- Averaged wave transmission coefficient is of about 0.43 and about 0.62 for the emerged and the submerged configurations respectively.

- Among the tested theoretical relationships available in the scientific literature, the Buccino \& Calabrese (2007)'s law is the best fit of the measured transmission coefficient for the submerged configurations; no good results were found for emerged configurations (small fitting parameters, very scattered data).

- The averaged value of the introduced wave "net transmission coefficient" is of about 0.51 and about 0.71 for the emerged and the submerged configurations respectively.

- The Van der Meer (1990)'s theoretical relationships fits absolutely very well the "net transmission coefficient" data of the submerged structure configurations; again no good results were found for emerged configurations (very poor fit parameters, very scattered data).

- Submerged configurations show larger shoreline retreats than the emerged ones at the same position and for the same wave attack conditions.

- Onshore configuration of barriers, of same type and similar section, seems to induce slightly better environmental consequences results, in terms of cross-shore wave reduction, short-term shoreline response and long-period beach evolution, with respect to the offshore position.

Ultimately:

- As obviously expected, submerged breakwaters have less defence efficiency than emerged ones.

- Onshore positions of defence breakwaters are more efficacious than the offshore ones.

Finally, for an engineering case, because of the breakwaters being studied will be designed as an array of contiguous barriers with intermediate narrow gaps, to favour navigation and water circulation, hence the problem is also planimetric and, in this case, like the described one, a 3D experimental verification is appropriate. For the analyzed protected beach of Gabicce Mare a dedicated laboratory study in a wave basin was performed at the L.I.C. in Bari (Italy).

\section{ACKNOWLEDGMENTS}

Thanks to Dr. Eng. Vincenzo Marzialetti of the Regione Marche.

\section{REFERENCES}

Autorità di bacino della Regione Marche. 2005. Piano di gestione integrata delle aree costiere. http://www.autoritabacino.marche.it/costa/piano/index.htm.

Battjes, J.A., and S. Beji. 1991. Spectral evolution in waves traveling over a shoal, Proceedings of the Nonlinear Water Waves Workshop, Bristol, 11-19.

Buccino, M., and M.Calabrese. 2007. Conceptual approach for prediction of wave transmission at lowcrested breakwaters, Journal of waterway, port, coastal and ocean engineering, 133 (3), 213-224.

Burcharth, H.F., S.J.Hawkins, B. Zanuttigh, and A. Lamberti. 2007. Environmental Design Guidelines for Low Crested Coastal Structures, Elsevier, pp. 400.

Calabrese, M., D. Vicinanza, and M. Buccino. 2005. Verification and recalibration of an engineering method for predicting 2D wave setup behind submerged breakwater, Proceedings of International Coastal Symposium '05, www.itv.is/ics2005.

Gonzales, M., R. Medina and M. A. Losada. 1999. Equilibrium beach profile model for perched beaches, Coastal Engineering, 36, 342-357. 
ISPRA. 2012. Historical archive - marigraphic and wavemetre data, www.idromare.it.

Istituto di idraulica dell'Università degli studi di Ancona. 2001. Studi, indagini e modelli matematici finalizzati alla redazione del Piano di difesa della costa, www.autoritabacino.marche.it/costa.htm.

Kraus, N.C. 1992. Engineering approaches to cross-shore sediment transport processes, Proceedings of the Short Course of the 23rd International Conference on Coastal Engineering, ASCE, 175-209.

Kriebel, D.L., and R. G. Dean. 1993. Convolution method for time-dependent beach-profile response, Journal of waterway, port, coastal and ocean engineering, 119 (2), 204-227.

Larson, H., and N. C. Kraus. 1989. Sbeach: numerical model for simulating storm induced beach change, CERC Report 89-9, US Corps of Engineers.

Larson, H., H. Hanson, and N.C. Kraus. 1997. Analytical solutions of the one-line model of shoreline change near coastal structures, J. of waterway, port, coastal and ocean eng., 123 (4), 180-191.

Lorenzoni, C., P. Perucci, and M. Riccioni. 1987. Ripascimento artificiale dei litorali marchigiani: criteri di progetto, modalità di esecuzione e conseguente evoluzione delle spiagge, Atti del $\mathrm{IV}^{\circ}$ Colloquio Nazionale A.I.O.M., Ancona, parte I, 196-221.

Lorenzoni, C., and A. Mancinelli. 2002. Erosione e opere di difesa per il litorale: la costa delle Marche, Orli d'acqua: il disegno della costa e della città porto, Ist. disegno, architett. e urbanistica, 73-96.

Lorenzoni, C., A. Piattella, L. Soldini, A. Mancinelli, and M. Brocchini. 2005. An experimental investigation of the hydrodynamic circulation in the presence of submerged breakwaters, Proceed. of the 5th International Symposium on Ocean Measurements and Analysis, Paper 125.

Lorenzoni, C., A. Mancinelli, M. Postacchini, M. Mattioli, L. Soldini, and S. Corvaro. 2009. Experimental tests on sandy beach model protected by low-crested structures, Proceedings of the 4th International Short Conference on Applied Coastal Research, Barcelona, Spain, 310-322.

Lorenzoni, C., L. Soldini, M. Brocchini, A. Mancinelli, M. Postacchini, E. Seta, and S. Corvaro. 2010. Working of defence coastal structures dissipating by macroroughness, Journal of Waterway, Port, Coastal, and Ocean Engineering, 136 (2), 79-90.

Mancinelli, A., C. Lorenzoni, and L. Soldini. 2000. Evoluzione dei profili di spiaggia in presenza di barre o barriere artificiali sommerse, Atti del XXVII ${ }^{\circ}$ Convegno di idraulica e costruzioni idrauliche, Genova, IV, 277-285.

Pilarczyk, K.W. 2003.Design of low-crested (submerged) structures - an overview, Proceedings of the $6^{\text {th }}$ International Conference on Coastal and Port Engineering in Developing Countries, 1-16.

Postacchini, M., C. Lorenzoni, A. Mancinelli, and M. Brocchini. 2010. Some Experimental Results on the Efficiency of Different Breakwater Configurations, Atti del XXXII ${ }^{\circ}$ Convegno Nazionale di Idraulica e Costruzioni idrauliche, CD-ROM, B0150.pdf.

Postacchini, M., M. Brocchini, S. Corvaro, C. Lorenzoni, and A. Mancinelli. 2011. Comparative analysis of sea wave dissipation induced by three flow mechanisms, Journal of Hydraulic Research, 49 (4), 554-561.

Ruol, P., A. Faedo, and A. Paris. 2003. Prove sperimentali sul comportamento di una scogliera a cresta bassa e sul fenomeno del piling-up a tergo di essa, Studi Costieri, 7, 41-59.

Soldini, L., C. Lorenzoni, M. Brocchini, A. Mancinelli, and L. Cappietti. 2009. Modeling of the wave setup inshore of an array of submerged breakwaters, Journal of waterway, port, coastal and ocean engineering, 135 (2), 38-51.

Van der Meer, J.W. 1990. Data on wave transmission due to overtopping, Delft Hydraulics Rep. H986.

Van der Meer, J.W., R. Briganti, B. Zanuttigh, and B. Wang. 2005. Wave transmission and reflection at low-crested structures: design formulae, oblique wave attack and spectral change, Coastal Engineering, 52, 915-929. 